\title{
Correction to: Risk Prediction of New Adjacent Vertebral Fractures After PVP for Patients with Vertebral Compression Fractures: Development of a Prediction Model
}

\author{
Bin-Yan Zhong ${ }^{1} \cdot$ Shi-Cheng He ${ }^{1} \cdot$ Hai-Dong Zhu ${ }^{1} \cdot$ Chun-Gen $\mathrm{Wu}^{2} \cdot$ Wen Fang ${ }^{1} \cdot$ Li Chen $^{1} \cdot$ Jin-He Guo ${ }^{1} \cdot$ \\ Gang Deng ${ }^{1} \cdot$ Guang-Yu Zhu ${ }^{1} \cdot$ Gao-Jun Teng ${ }^{1}$
}

Published online: 16 May 2018

(C) Springer Science+Business Media, LLC, part of Springer Nature and the Cardiovascular and Interventional Radiological Society of Europe (CIRSE) 2018

\section{Correction to:}

Cardiovasc Intervent Radiol (2017) 40:277-284 https://doi.org/10.1007/s00270-016-1492-1

The original version of this article unfortunately contained a mistake. The Acknowledgements were incorrect.

Acknowledgements This study was funded by the National Basic Research Program of China (973 Program \# 2013CB733800, 2013733803), the National High-tech Research Foundation of China (863 project
\#2012AA022701), the National Scientific and Technical Achievement Translation Foundation ([2012]258), the Jiangsu Provincial Special Program of Medical Science (BL2013029), the National Natural Science Foundation of China (81230034, 81171434), the Fundamental Research Funds for the Central Universities, and the Scientific Research Innovation Program for College and University Graduates of Jiangsu Province (KYZZ16_0133). Funding sources had no involvement in the financial support for the conduct of the research and preparation of the article.

The original article can be found online at https://doi.org/10.1007/ s00270-016-1492-1.

Gao-Jun Teng

gjteng@vip.sina.com

1 Department of Radiology, Medical School, Zhongda Hospital, Southeast University, 87 DingjiaqiaoRoad, Nanjing 210009, China

2 Department of Diagnostic and Interventional Radiology, Shanghai Jiao Tong University Affiliated Sixth People's Hospital, No. 600 Yi Shan Road, Shanghai 200233, China 